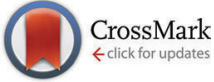

Cite this: Phys. Chem. Chem. Phys., 2015, 17, 9564

Received 19th February 2015 , Accepted 2nd March 2015

DOI: $10.1039 /$ c5cp01038a

www.rsc.org/pccp

\title{
Mechanistic aspects of the gas-phase coupling of thioanisole and chlorobenzene to dibenzothiophene catalyzed by atomic $\mathrm{Ho}^{+}+*$
}

\author{
Shaodong Zhou, Maria Schlangen and Helmut Schwarz*
}

Mechanistic aspects of the novel gas-phase generation of dibenzothiophene via coupling of thioanisole and chlorobenzene, employing atomic $\mathrm{Ho}^{+}$as a catalyst, have been investigated using Fourier-transform ion cyclotron resonance mass spectrometry in conjunction with density functional theory (DFT) calculations.

\section{Introduction}

Sulfur heterocycles are important building blocks of various chemical products, including organic thin-film transistors, ${ }^{1,2}$ metal extracting reagents, ${ }^{3,4}$ or bioactive and medicinally relevant compounds. $^{5-8}$ Consequently, methodological aspects related to the formation of organosulfur heterocyclic rings have attracted much attention. For the synthesis of sulfur-containing heterocycles usually metal sulfides, thioesters, or thioethers are employed as starting materials, and first- or second-row transition-metal complexes serve as catalysts. To achieve $\mathrm{C}-\mathrm{C}^{9-12}$ or $\mathrm{C}-\mathrm{S}^{13-20}$ coupling involved in the ring closure process, activation of $\mathrm{C}-\mathrm{H},{ }^{9-20} \mathrm{C}-\mathrm{X}(\mathrm{X}=\mathrm{Br} \text { or } \mathrm{I})^{15,18,20}$ or $\mathrm{C}-\mathrm{S}^{14,17}$ bonds is a prerequisite. While gas-phase investigations proved helpful to obtain mechanistic aspects for numerous processes, except for a few reports on the formation of sulfur heterocycles in the gas phase, ${ }^{21}$ a more detailed understanding of the elementary steps is lacking.

In a previous study on the reactions of atomic $\mathrm{Ln}^{+}$with chlorobenzene, ${ }^{22}$ strong indications have been found that $\mathrm{Ho}^{+}$ generates efficiently the insertion product $\mathrm{Ho}\left(\mathrm{C}_{6} \mathrm{H}_{5}\right)(\mathrm{Cl})^{+}$which then promotes $\mathrm{HCl}$ elimination in a secondary reaction with chlorobenzene; further, intriguing coupling processes have been observed in preliminary studies on consecutive reactions of $\mathrm{Ln}^{+}$with chlorobenzene and thioanisole in which $\mathrm{Ho}^{+}$exhibited the highest efficiency. Thus, we explored these reactions in more detail, and here we describe a gas-phase approach of sequential $\mathrm{C}-\mathrm{C}$ and $\mathrm{C}-\mathrm{S}$ coupling to generate dibenzothiophene by using thioanisole and chlorobenzene as substrates and exploiting atomic $\mathrm{Ho}^{+}$as a catalyst. Gas-phase studies employing atomic

Institut für Chemie, Technische Universität Berlin, Straße des 17. Juni 135,

10623 Berlin, Germany. E-mail: helmut.schwarz@tu-berlin.de

$\dagger$ Dedicated to Professor R. N. Zare, Stanford University, on the occasion of his 75th birthday.

\$ Electronic supplementary information (ESI) available: Experimental \& computational details, and figures. See DOI: 10.1039/c5cp01038a catalysts ${ }^{23}$ recently regained interest ${ }^{24}$ in the context of "singleatom catalysis". ${ }^{25}$

\section{Results and discussion}

Coupling of thioanisole and chlorobenzene is achieved via two steps: first, $\mathrm{Ho}^{+}$reacts with thioanisole to produce an ionic precursor, which subsequently undergoes reaction with chlorobenzene to re-generate $\mathrm{Ho}^{+}$under the elimination of the neutral heterocyclic product.

\section{Reactions of $\mathrm{Ho}^{+}$with thioanisole}

1.1 Ion-molecule reactions of $\mathrm{Ho}^{+}$with thioanisole. Three primary channels were observed in the thermal reaction of $\mathrm{Ho}^{+}$ with thioanisole introduced via a leak valve at a stationary pressure of $p=1.0 \times 10^{-8}$ bar, i.e. reactions (1)-(3); the overall efficiency amounts to $30 \%$, relative to the collision rate. ${ }^{26}$

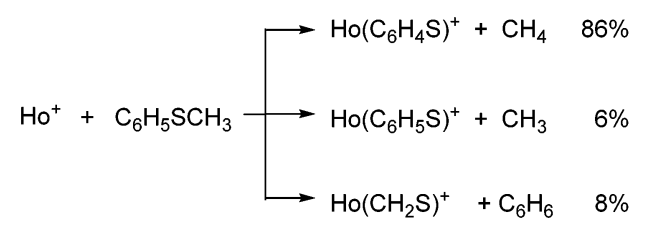

$\mathrm{C}-\mathrm{S}$ bond activation is involved in all three channels; in addition, $\mathrm{C}-\mathrm{H}$ bond activation takes place in reactions (1) and (3), respectively. Structural information on the cationic product ions as well as mechanistic aspects of these processes were obtained from DFT calculations. The potential-energy surfaces (PESs) together with structural data of the associated intermediates and transition structures are shown in Fig. 1 for the generations of $\mathrm{Ho}\left(\mathrm{C}_{6} \mathrm{H}_{4} \mathrm{~S}\right)^{+}$ and $\mathrm{Ho}\left(\mathrm{C}_{6} \mathrm{H}_{5} \mathrm{~S}\right)^{+}$, and in Fig. 2 two alternative pathways for the formation of $\mathrm{Ho}\left(\mathrm{CH}_{2} \mathrm{~S}\right)^{+}$are presented.

1.2 Pathways to form $\mathrm{Ho}\left(\mathrm{C}_{6} \mathrm{H}_{4} S\right)^{+}$and $\mathrm{Ho}\left(\mathrm{C}_{6} \mathrm{H}_{5} \mathrm{~S}\right)^{+}$. Several coordination modes, e.g. $\eta^{2}$ or $\eta^{6}$ coordination to the ring, 


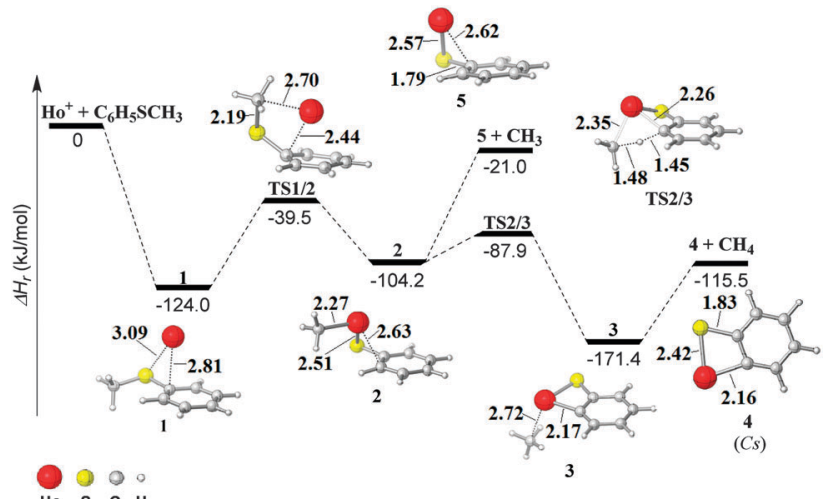

Fig. 1 PESs and structural information of the associated coordinates for the generations of $\mathrm{Ho}_{0}\left(\mathrm{C}_{6} \mathrm{H}_{4} \mathrm{~S}\right)^{+}$and $\mathrm{Ho}\left(\mathrm{C}_{6} \mathrm{H}_{5} \mathrm{~S}\right)^{+}$. Selected bond lengths are given in $\AA$; for the sake of clarity, charges are omitted.

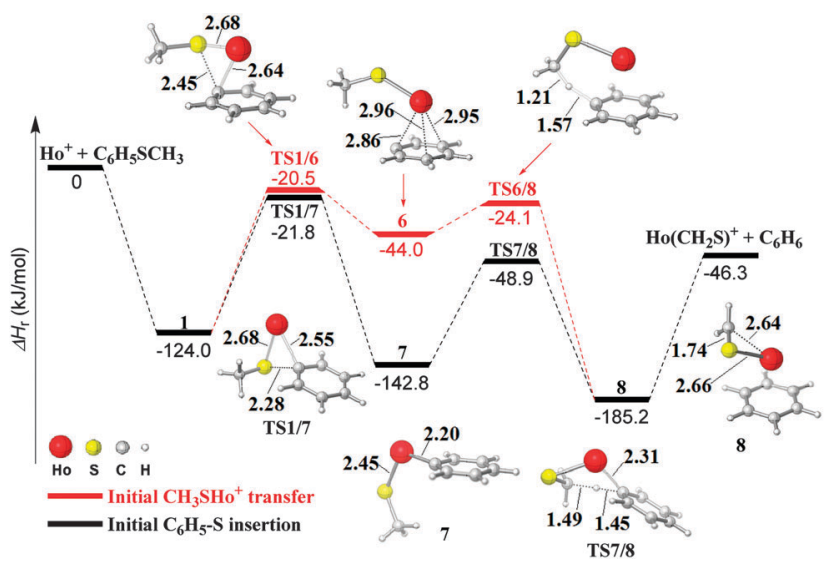

Fig. 2 PESs and structural information of the associated coordinates for the generation of $\mathrm{Ho}\left(\mathrm{CH}_{2} \mathrm{~S}\right)^{+}$. Selected bond lengths are given in $\AA$; for the sake of clarity, charges are omitted.

attachment of the cation to the sulfur atom etc., have been taken into account for the generation of an encounter complex of $\mathrm{Ho}^{+}$with thioanisole; however, irrespective of all starting structures considered, as a result of the optimization, only 1 has been identified as encounter complex. In $\mathbf{1}, \mathrm{Ho}^{+}$is $\eta^{2}$ coordinated to the sulfur and the ipso-carbon atom of the phenyl ring. This intermediate serves as the starting point for all three reaction channels (1)-(3). Subsequent to the adduct formation, the generations of both $\mathrm{Ho}\left(\mathrm{C}_{6} \mathrm{H}_{4} \mathrm{~S}\right)^{+}$and $\mathrm{Ho}\left(\mathrm{C}_{6} \mathrm{H}_{5} \mathrm{~S}\right)^{+}$, reactions (1) and (2), proceed by the oxidative insertion of $\mathrm{Ho}^{+}$ into the $\mathrm{S}-\mathrm{CH}_{3}$ bond thus forming intermediate 2 . Since ground state $\mathrm{Ho}^{+}$possesses a $4 \mathrm{f}^{11} 5 \mathrm{~d}^{0} 6 \mathrm{~s}^{1}$ electronic configuration, one $4 \mathrm{f}$ electron of $\mathrm{Ho}^{+}$has to be promoted to a non-f valence orbital to allow the formation of 2 in which holmium is engaged in forming two $\sigma$ bonds. NBO analysis of the IRC coordinates of TS1/2 indicates that the electron promotion of $\mathrm{Ho}^{+}$from a $4 \mathrm{f}$ orbital to a non-f valence orbital occurs after cleavage of the $\mathrm{S}-\mathrm{CH}_{3}$ bond. Thus, both the promotion energy (PE) of $\mathrm{Ho}^{+}$to attain a $4 \mathrm{f}^{10} 5 \mathrm{~d}^{1} 6 \mathrm{~s}^{1}$ configuration $\left(158 \mathrm{~kJ} \mathrm{~mol}^{-1}\right.$ (ref. 27)) as well as the $\mathrm{S}-\mathrm{CH}_{3}$ bond dissociation energy $\left(\mathrm{BDE}\left(\mathrm{S}-\mathrm{CH}_{3}\right), 278 \mathrm{~kJ} \mathrm{~mol}^{-1}\right.$ (ref. 28)) accompanied by distortion of the anisole molecule contribute to the energy barrier associated with TS1/2. While the homolytic cleavage of the $\mathrm{Ho}-\mathrm{CH}_{3}$ bond of intermediate 2 results in the formation of holmium benzenethiolate $\mathrm{Ho}\left(\mathrm{C}_{6} \mathrm{H}_{5} \mathrm{~S}\right)^{+}$ (5), generation of $\mathrm{Ho}\left(\mathrm{C}_{6} \mathrm{H}_{4} \mathrm{~S}\right)^{+}$(4) proceeds via a metal mediated $\sigma$-bond metathesis process $\mathbf{2} \rightarrow \mathbf{3}$, in which a hydrogen-atom transfer takes place from the ortho-position of the phenyl ring to the methyl group via TS2/3. Subsequently, the elimination of methane gives rise to the product ion 4. In line with the experimental results, both reactions are exothermic and thus energetically accessible under thermal conditions; moreover, the preferred elimination of $\mathrm{CH}_{4}$, observed in the experiments, agrees with the more energy demanding cleavage of the $\mathrm{Ho}_{-} \mathrm{CH}_{3}$ bond of 2, accompanied with the generation of $\mathrm{Ho}\left(\mathrm{C}_{6} \mathrm{H}_{5} \mathrm{~S}\right)^{+}$, as compared to the liberation of $\mathrm{CH}_{4}$ along the sequence $2 \rightarrow 3 \rightarrow 4$. Considering the relative energies of TS2/3 and TS1/2 $\left(-87.9 \mathrm{~kJ} \mathrm{~mol}^{-1}\right.$ versus $-39.5 \mathrm{~kJ} \mathrm{~mol}^{-1}$ ), insertion of $\mathrm{Ho}^{+}$into the $\mathrm{S}-\mathrm{CH}_{3}$ bond constitutes the rate-limiting step for the generation of the major product $\mathrm{Ho}\left(\mathrm{C}_{6} \mathrm{H}_{4} \mathrm{~S}\right)^{+}$.

1.3 Generation of $\mathbf{H o}\left(\mathrm{CH}_{2} \mathrm{~S}\right)^{+}$. Two pathways have been located to produce $\mathrm{Ho}\left(\mathrm{CH}_{2} \mathrm{~S}\right)^{+}$. The first one commences with insertion of $\mathrm{Ho}^{+}$into the $\mathrm{S}-\mathrm{C}_{6} \mathrm{H}_{5}$ bond, while in the second one the $\mathrm{CH}_{3} \mathrm{~S}$ group remains bound in the migration of $\mathrm{Ho}^{+}$to the top of the phenyl ring. As mentioned above, for the insertion process one electron of $\mathrm{Ho}^{+}$has to be promoted from a $4 \mathrm{f}$ orbital to a non-f valence orbital; according to NBO analysis, the promotion takes place in proceeding from TS1/7 to intermediate 7 after cleavage of the $\mathrm{S}-\mathrm{C}_{6} \mathrm{H}_{5}$ bond; then, again, one electron re-occupies the $4 \mathrm{f}$ orbital of $\mathrm{Ho}^{+}$in the step TS7/8 $\rightarrow$ 8. In contrast, a $4 \mathrm{f} \rightarrow$ non-f promotion is not necessary for the pathway initiated by migration of the whole $\mathrm{CH}_{3} \mathrm{SHo}^{+}$unit; here, throughout the reaction sequence $\mathbf{1} \rightarrow \mathbf{6} \rightarrow \mathbf{8}$ the holmium atom remains covalently bound only to the sulfur atom. Considering the comparable energies of TS1/6, TS1/7, and TS6/8, generation of $\mathrm{Ho}\left(\mathrm{CH}_{2} \mathrm{~S}\right)^{+}$is influenced by several factors, including the $\mathrm{BDE}\left(\mathrm{C}_{6} \mathrm{H}_{5}-\mathrm{S}\right)\left(357 \mathrm{~kJ} \mathrm{~mol}^{-1}\right.$ (ref. 28)), and $\mathrm{BDE}\left(\mathrm{Ho}^{+} \mathrm{SCH}_{2}-\mathrm{H}\right)$, as well as the $\mathrm{PE}$ of $\mathrm{Ho}^{+}$to attain a $4 \mathrm{f}^{10} 5 \mathrm{~d}^{1} 6 \mathrm{~s}^{1}$ configuration. Finally, compared to the formation of $\mathrm{Ho}\left(\mathrm{C}_{6} \mathrm{H}_{4} \mathrm{~S}\right)^{+}$, the generation of $\mathrm{Ho}\left(\mathrm{CH}_{2} \mathrm{~S}\right)^{+}$is energetically less favorable, in agreement with its lower branching ratio; also, the energetics for the generations of $\mathrm{Ho}\left(\mathrm{C}_{6} \mathrm{H}_{5} \mathrm{~S}\right)^{+}$and $\mathrm{Ho}\left(\mathrm{CH}_{2} \mathrm{~S}\right)^{+}$are in line with their similar branching ratios.

\section{Reactions of $\mathrm{Ho}\left(\mathrm{C}_{6} \mathrm{H}_{4} \mathrm{~S}\right)^{+}$with chlorobenzene}

For probing the thermal reactions of $\mathrm{Ho}\left(\mathrm{C}_{6} \mathrm{H}_{4} \mathrm{~S}\right)^{+}$with chlorobenzene, the thermalized, mass-selected precursor $\mathrm{Ho}\left(\mathrm{C}_{6} \mathrm{H}_{4} \mathrm{~S}\right)^{+}$is exposed to chlorobenzene which is introduced via a leak valve and present in the ICR cell at a stationary pressure of $p=1.0 \times$ $10^{-8}$ bar. The overall reaction efficiency amounts to $7 \%$, and three primary product channels were observed, i.e. reaction (4)-(6). Performing the same experiments without thermalization of

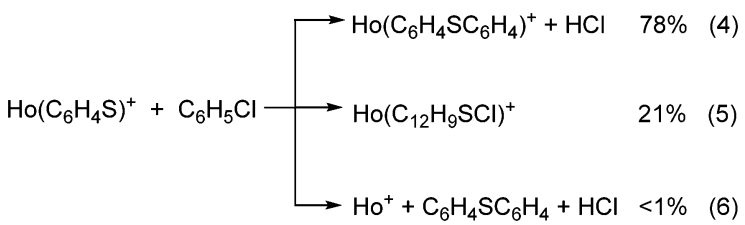


the precursor $\mathrm{Ho}\left(\mathrm{C}_{6} \mathrm{H}_{4} \mathrm{~S}\right)^{+}$, the branching ratio of reaction (6) increases up to $27 \%$, while the branching ratios of reaction (4) and (5) decrease to $63 \%$ and $10 \%$, respectively.

The assignment of the $\left[\mathrm{C}_{12}, \mathrm{H}_{8}, \mathrm{~S}\right]$ unit as a dibenzothiophene ligand $\left(\mathrm{C}_{6} \mathrm{H}_{4} \mathrm{SC}_{6} \mathrm{H}_{4}\right)$ in the product ion of reaction (4) as well as for the neutral molecule of reaction (6) is based on the following considerations. First, if $\left[\mathrm{C}_{12}, \mathrm{H}_{8}, \mathrm{~S}\right]$ corresponds to an intact $\left[\mathrm{C}_{12}, \mathrm{H}_{8}, \mathrm{~S}\right]$ ligand we assume a dibenzothiophene structure since the generation of isomeric naphthothiophene is much more complicated starting from the two substrates employed in the experiments. The next and even more important aspect concerns the question if $\left[\mathrm{C}_{12}, \mathrm{H}_{8}, \mathrm{~S}\right]$ represents a single ligand, or if it is composed of two individual units, e.g. $\mathrm{C}_{6} \mathrm{H}_{4} \mathrm{~S}$ and $\mathrm{C}_{6} \mathrm{H}_{4}$. To this end, the major product ion $\mathrm{Ho}\left(\mathrm{C}_{12}, \mathrm{H}_{8}, \mathrm{~S}\right)^{+}$has been mass selected and subjected to collision-induced dissociation (CID). At a collision energy $E_{\text {coll }}=3.6 \mathrm{eV}$ (given in the center-of-mass frame), $\mathrm{Ho}^{+}$ and $\mathrm{HoS}^{+}$are produced upon collision with argon in a ratio of about 9:1; applying lower collision energies, $\mathrm{Ho}^{+}$corresponds to the only fragment ion generated. From the above results, the following conclusions can be drawn: (i) $\mathrm{Ho}\left(\mathrm{C}_{12}, \mathrm{H}_{8}, \mathrm{~S}\right)^{+}$corresponds to a complex with a single ligand which we assign to dibenzothiophene; the latter is generated in the reaction of thermalized $\mathrm{Ho}\left(\mathrm{C}_{6} \mathrm{H}_{4} \mathrm{~S}\right)^{+}$with chlorobenzene under the elimination of $\mathrm{HCl}$, and (ii) "bare" $\mathrm{Ho}^{+}$is formed as product ion via the consecutive eliminations of $\mathrm{HCl}$ and dibenzothiophene. Further, the alternative formation of $\left[\mathrm{Ho}\left(\mathrm{C}_{6} \mathrm{H}_{4} \mathrm{~S}\right)\left(\mathrm{C}_{6} \mathrm{H}_{4}\right)\right]^{+}$, possessing two individual ligands, e.g. $\mathrm{C}_{6} \mathrm{H}_{4} \mathrm{~S}$ and benzyne, would result in the formations of both fragment ions $\mathrm{Ho}\left(\mathrm{C}_{6} \mathrm{H}_{4} \mathrm{~S}\right)^{+}$and $\mathrm{Ho}\left(\mathrm{C}_{6} \mathrm{H}_{4}\right)^{+}$upon CID. Moreover, the generation of the $\mathrm{Ho}\left(\mathrm{C}_{6} \mathrm{H}_{4} \mathrm{~S}\right)\left(\mathrm{C}_{6} \mathrm{H}_{4}\right)^{+}+\mathrm{HCl}$ is, according to the calculation, endothermic by $190.1 \mathrm{~kJ} \mathrm{~mol}^{-1}$ (for more structural details of $\mathrm{Ho}\left(\mathrm{C}_{6} \mathrm{H}_{4} \mathrm{~S}\right)\left(\mathrm{C}_{6} \mathrm{H}_{4}\right)^{+}$, see ESI $\left.\$\right)$. Finally, the possible charge transfer product, $\mathrm{C}_{6} \mathrm{H}_{4} \mathrm{SC}_{6} \mathrm{H}_{4}{ }^{+}$, was not observed, in line with the much higher ionization energy of dibenzothiophene $\left(8.44 \mathrm{eV}^{29}\right)$ as compared to that of holmium $\left(6.0 \mathrm{eV}^{30}\right)$.

Two chemically plausible pathways, (a) and (b), are proposed for the generation of $\mathrm{Ho}\left(\mathrm{C}_{6} \mathrm{H}_{4} \mathrm{SC}_{6} \mathrm{H}_{4}\right)^{+}$possessing a $\mathrm{C}_{6} \mathrm{H}_{4} \mathrm{SC}_{6} \mathrm{H}_{4}$ ligand as illustrated in Scheme 1 ; both routes are initiated by $\sigma$ bond metathesis under cleavage of the Ho-S and Ho- $\mathrm{C}$ bonds of the complex $\mathrm{Ho}\left(\mathrm{C}_{6} \mathrm{H}_{4} \mathrm{~S}\right)^{+}$, respectively. The PESs and the structural information of the associated intermediates and transition structures for the two pathways are shown in Fig. 3, and the encounter complex 9 serves as a common starting point. The TS for the Ho-S bond cleavage (TS9/10) is much higher in energy relative to the entrance channel as well as to the alternative $\mathrm{Ho}-\mathrm{C}$

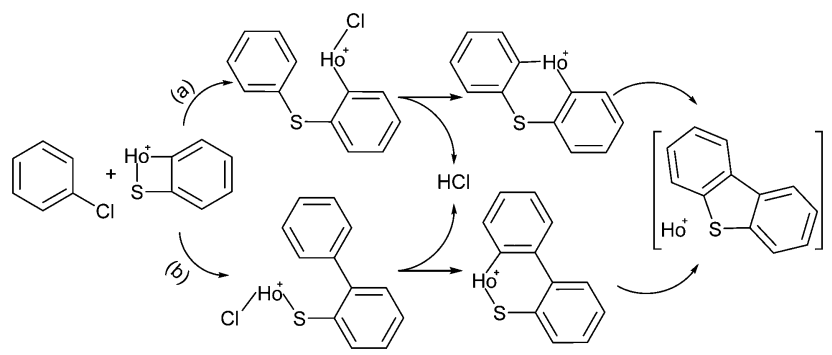

Scheme 1 Plausible pathways for the generation of $\mathrm{Ho}_{0}\left(\mathrm{C}_{6} \mathrm{H}_{4} \mathrm{SC}_{6} \mathrm{H}_{4}\right)^{+}$.

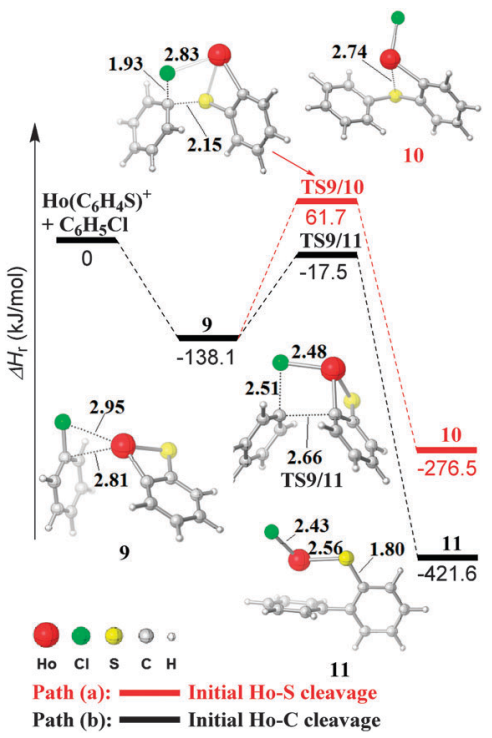

Fig. 3 PESs and structural information of the associated coordinates for the initial $\mathrm{Ho}-\mathrm{C}$ and $\mathrm{Ho}-\mathrm{S}$ cleavages of $\mathrm{Ho}_{0}\left(\mathrm{C}_{6} \mathrm{H}_{4} \mathrm{~S}\right)^{+}$upon its reaction with chlorobenzene. Selected bond lengths are given in $\AA$; charges are omitted for the sake of clarity.

bond cleavage proceeding via TS9/11 (61.7 $\mathrm{kJ} \mathrm{mol}^{-1}$ versus $-17.5 \mathrm{~kJ} \mathrm{~mol}^{-1}$ ), i.e. dehydrochlorination is accessible under thermal conditions only via path (b) $(\mathbf{9} \rightarrow$ TS9/11 $\rightarrow$ 11); therefore, it is only this route which has been considered further in the calculations of the subsequent reaction steps. The reason for the much higher barrier of the Ho-S bond cleavage (TS9/10) as compared to the Ho-C bond (TS9/11) is probably related to the stronger Ho-S bond compared to the Ho-C bond reflecting electronegativity differences between sulfur and carbon; unfortunately, the respective bonddissociation energies are not reported in the literature.

Subsequent to the formation of intermediate 11, dehydrochlorination proceeds either directly via a hydrogen atom transfer from an ortho-position of the phenyl ring to the chloride ligand $(\mathbf{1 1} \rightarrow \mathbf{1 2})$, or may be preceded by hydrogen scrambling within the original chlorobenzene entity $(11 \rightarrow 13 \rightarrow 14 \rightarrow 15 \rightarrow 16)$. The PESs for these processes and structural information of the associated intermediates and transition structures for the generation of $\mathrm{Ho}\left(\mathrm{C}_{6} \mathrm{H}_{4} \mathrm{SC}_{6} \mathrm{H}_{4}\right)^{+}$as well as the intermediates for hydrogen scrambling along $13 \rightleftharpoons \rightleftharpoons 16$ are shown in Fig. 4; structural details of the transition structures involved in the hydrogen scrambling are given in ESI. $\neq$ According to the calculations, hydrogen scrambling is less energy demanding than the loss of $\mathrm{HCl}$. The H/D scrambling has been verified by labeling experiments: in the reactions of $\mathrm{Ho}\left(\mathrm{C}_{6} \mathrm{H}_{4} \mathrm{~S}\right)^{+}$with 3,5- $d_{2}$-1-chlorobenzene and 4-d-1-chlorobenzene, eliminations of both $\mathrm{HCl}$ and $\mathrm{DCl}$ are observed for either substrate; the ratios of $\mathrm{HCl} / \mathrm{DCl}$ elimination from 3,5- $d_{2}$-1-chlorobenzene and from 4- $d$-1-chlorobenzene amount to $84: 16$ and $87: 13$, respectively. To quantitatively analyse these results in a kinetic modeling, ${ }^{31-35}$ hydrogen migration along the phenyl ring is treated as a complete $\mathrm{H} / \mathrm{D}$ scrambling processes; further, the ratio for a direct $\mathrm{HCl} / \mathrm{DCl}$ elimination versus $\mathrm{H} / \mathrm{D}$ scrambling prior to $\mathrm{HCl} / \mathrm{DCl}$ elimination as well as a kinetic isotope effect (KIE) have been fitted to the experimental data for 


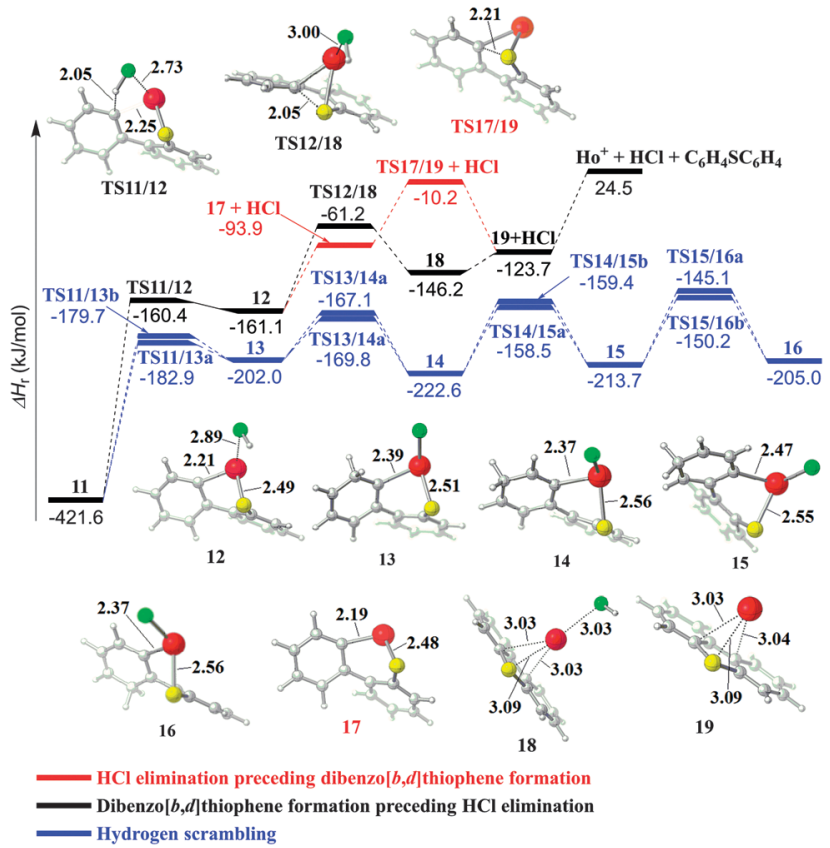

Fig. 4 PESs of the reactions starting from intermediate 11 as well as the structural information of some key coordinates; the notations $a$ and $b$ for the transition structures stand for the hydrogen migrations on both sites of the ring, respectively. Selected bond lengths are given in $\AA$; charges are omitted for the sake of clarity. For further structural information, see Fig. S2 of ESI.‡

both isotopologues. It turned out that the experimental data can be best modeled with assuming $\mathrm{KIE}=1$ and a branching ratio of $45 \%$ for $\mathrm{H} / \mathrm{D}$ scrambling processes versus direct $\mathrm{HCl}$ / DCl elimination. A KIE $=1$ is in agreement with the theoretical results, in that $\mathrm{C}-\mathrm{H}(\mathrm{D})$ bond activation does not correspond to the rate-limiting step in the liberation of $\mathrm{H}(\mathrm{D}) \mathrm{Cl}$ and the generation of $\mathrm{Ho}\left(\mathrm{C}_{6} \mathrm{H}_{4} \mathrm{SC}_{6} \mathrm{H}_{4}\right)^{+}$.

After having formed 12, the next step corresponds to the construction of the thiophene ring; there are two variants in regard to the loss of $\mathrm{HCl}$ which can occur before or after the ring closure. The direct formation of the thiophene ring proceeds via TS12/18 to form 18, and subsequent elimination of $\mathrm{HCl}$ generates 19; alternatively, direct liberation of $\mathrm{HCl}$ from 12 gives rise to 17 which subsequently rearranges via $\mathbf{T S 1 7 / 1 9}$ to the complex 19 (see Fig. 4); both processes are accessible at thermal conditions. Thus, according to the calculation, the observed ionic product $\mathrm{Ho}\left(\mathrm{C}_{6} \mathrm{H}_{4} \mathrm{SC}_{6} \mathrm{H}_{4}\right)^{+}$may correspond to a mixture of 17 and 19. Regarding the formation of $\mathrm{Ho}^{+}+\mathrm{HCl}+$ $\mathrm{C}_{6} \mathrm{H}_{4} \mathrm{SC}_{6} \mathrm{H}_{4}$, reaction (6), this has been calculated to be higher in energy by $25 \mathrm{~kJ} \mathrm{~mol}^{-1}$ as compared to the entrance channel, i.e. $\mathrm{Ho}\left(\mathrm{C}_{6} \mathrm{H}_{4} \mathrm{~S}\right)^{+}+\mathrm{C}_{6} \mathrm{H}_{5} \mathrm{Cl}$, and should thus not be observed under thermal conditions. Thus, assuming that the ions in the experiments are thermalized to room temperature possessing a kinetic energy of $3 R T=7.4 \mathrm{~kJ} \mathrm{~mol}^{-1}$ at $298 \mathrm{~K}$, theory overestimates the relative energy of the exit channel.

Considering the overall process, i.e. $\mathrm{Ho}^{+}+\mathrm{C}_{6} \mathrm{H}_{5} \mathrm{SCH}_{3}+$ $\mathrm{C}_{6} \mathrm{H}_{5} \mathrm{Cl} \rightarrow \mathrm{Ho}^{+}+\mathrm{HCl}+\mathrm{C}_{6} \mathrm{H}_{4} \mathrm{SC}_{6} \mathrm{H}_{4}$, the atomic holmium cation $\mathrm{Ho}^{+}$serves as a catalyst, as illustrated in Scheme 2. However, the turnover number is limited by side reactions with both substrates

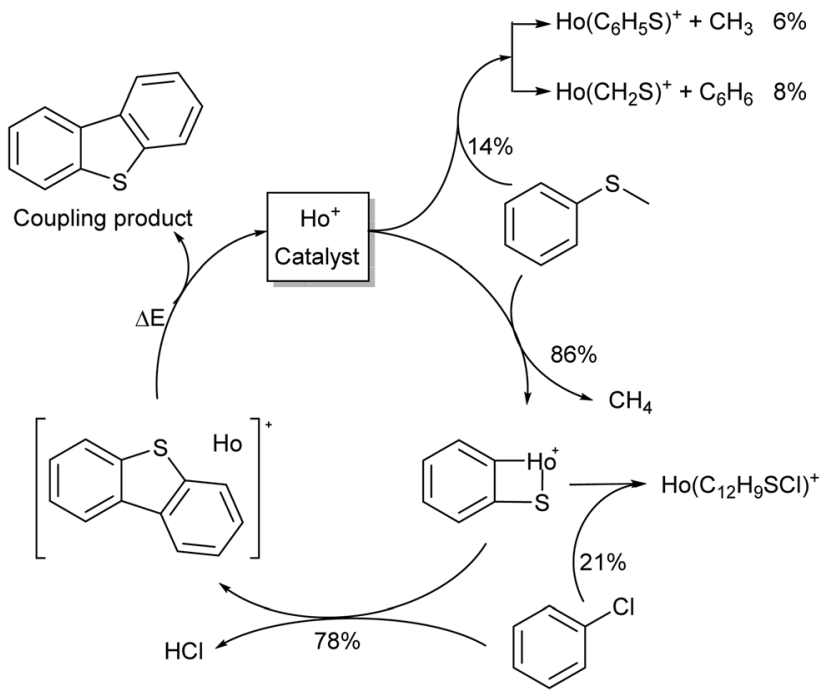

Scheme 2 Catalytic cycle for the coupling of thioanisole and chlorobenzene mediated by atomic $\mathrm{Ho}^{+}$as well as side reactions.

(processes (2), (3), and (5)), and the turn-over frequency is diminished due to the inefficient release of the neutral coupling product from 19 under the regeneration of $\mathrm{Ho}^{+}$ions to initiate the next catalytic cycle. As so often in heterogeneous catalysis, product release and regeneration of the active catalyst (i.e. $\mathrm{Ho}^{+}$) requires external energy. ${ }^{36-41}$ In addition, the presence of both substrates thioanisole and chlorobenzene at the same time in a "one-pot synthesis" allows for additional side reactions as $\mathrm{Ho}^{+}$can react with both precursors. Moreover, $\mathrm{Ho}\left(\mathrm{C}_{6} \mathrm{H}_{4} \mathrm{~S}\right)^{+}$can also react further with thioanisole to give higher order products. Thus, timing of the interaction of the catalyst with the two substrates needs to be well designed to improve the efficiency of the coupling process.

\section{Conclusion}

In this work, we present a novel gas-phase coupling of thioanisole and chlorobenzene to dibenzothiophene catalyzed by "bare" holmium cation $\mathrm{Ho}^{+}$and we address mechanistic aspects by DFT calculations and labeling experiments. The coupling is achieved via a two-step reaction: the first one corresponds to the reaction of $\mathrm{Ho}^{+}$ with thioanisole to generate $\mathrm{Ho}\left(\mathrm{C}_{6} \mathrm{H}_{4} \mathrm{~S}\right)^{+}$; subsequently, $\mathrm{Ho}\left(\mathrm{C}_{6} \mathrm{H}_{4} \mathrm{~S}\right)^{+}$ reacts with chlorobenzene to produce the final products. A combination of experimental and computational investigations, provides insight into the most likely reaction mechanisms. For the overall transformation, atomic $\mathrm{Ho}^{+}$serves as a catalyst which, however, is also engaged in side reactions with both substrates. Similar to heterogeneous catalysis, external energy is required to release the coupling product from the catalyst.

\section{Acknowledgements}

Generous financial support by the Fonds der Chemischen Industrie and the Deutsche Forschungsgemeinschaft ("UniCat") is appreciated. We thank Dr Thomas Weiske for technical assistance. 


\section{Notes and references}

1 P. Y. Huang, L. H. Chen, Y. Y. Chen, W. J. Chang, J. J. Wang, K. H. Lii, J. Y. Yan, J. C. Ho, C. C. Lee, C. Kim and M. C. Chen, Chem. - Eur. J., 2013, 19, 3721-3728.

2 E. L. Ratcliff, R. C. Bakus, G. C. Welch, T. S. van der Poll, A. Garcia, S. R. Cowan, B. A. MacLeod, D. S. Ginley, G. C. Bazan and D. C. Olson, J. Mater. Chem. C, 2013, 1, 6223-6234.

3 C. Freund, W. Porzio, U. Giovanella, F. Vignali, M. Pasini, S. Destri, A. Mech, S. Di Pietro, L. Di Bari and P. Mineo, Inorg. Chem., 2011, 50, 5417-5429.

4 C. Greco, G. Moro, L. Bertini, M. Biczysko, V. Barone and U. Cosentino, J. Chem. Theory Comput., 2014, 10, 767-777.

5 C. D. Jones, M. G. Jevnikar, A. J. Pike, M. K. Peters, L. J. Black, A. R. Thompson, J. F. Falcone and J. A. Clemens, J. Med. Chem., 1984, 27, 1057-1066.

6 J. K. Chakrabarti, T. M. Hotten and D. E. Tupper, US5229382A, 1990.

7 S. Martin-Santamaria, J. J. Rodriguez, S. de Pascual-Teresa, S. Gordon, M. Bengtsson, I. Garrido-Laguna, B. Rubio-Viqueira, P. P. Lopez-Casas, M. Hidalgo, B. de Pascual-Teresa and A. Ramos, Org. Biomol. Chem., 2008, 6, 3486-3496.

8 E. Bey, S. Marchais-Oberwinkler, M. Negri, P. Kruchten, A. Oster, T. Klein, A. Spadaro, R. Werth, M. Frotscher, B. Birk and R. W. Hartmann, J. Med. Chem., 2009, 52, 6724-6743.

9 A. R. Katritzky, R. A. Barcock, E. S. Ignatchenko, S. M. Allin, M. Siskin and C. W. Hudson, Energy Fuels, 1997, 11, 150-159.

10 C. L. Sun, Y. F. Gu, W. P. Huang and Z. J. Shi, Chem. Commun., 2011, 47, 9813-9815.

11 R. Samanta and A. P. Antonchick, Angew. Chem., Int. Ed., 2011, 50, 5217-5220.

12 R. Che, Z. Wu, Z. Li, H. Xiang and X. Zhou, Chem. - Eur. J., 2013, 20, 7258-7261.

13 Y. L. Mao and V. Boekelheide, Proc. Natl. Acad. Sci. U. S. A., 1980, 77, 1732-1735.

14 M. Black, J. I. G. Cadogan and H. Mcnab, J. Chem. Soc., Chem. Commun., 1990, 395-396.

15 L. Benati, R. Leardini, M. Minozzi, D. Nanni, P. Spagnolo, S. Strazzari and G. Zanardi, Org. Lett., 2002, 4, 3079-3081.

16 G. K. S. Prakash, C. Weber, S. Chacko and G. A. Olah, Org. Lett., 2007, 9, 1863-1866.

17 M. Black, J. I. G. Cadogan and H. Mcnab, Org. Biomol. Chem., 2010, 8, 2961-2967.

18 W. You, X. Y. Yan, Q. A. Liao and C. J. Xi, Org. Lett., 2010, 12, 3930-3933.
19 T. H. Jepsen, M. Larsen, M. Jorgensen, K. A. Solanko, A. D. Bond, A. Kadziola and M. B. Nielsen, Eur. J. Org. Chem., 2011, 53-57.

20 Z. J. Qiao, H. Liu, X. Xiao, Y. N. Fu, J. P. Wei, Y. X. Li and X. F. Jiang, Org. Lett., 2013, 15, 2594-2597.

21 M. M. Basher, Y. E. Corilo, R. Sparrapan, M. Benassi, R. Augusti, M. N. Eberlin and J. M. Riveros, J. Mass Spectrom., 2012, 47, 1526-1535.

22 S. Zhou, M. Schlangen and H. Schwarz, Chem. - Eur. J., 2015, 21, 2123-2131.

23 D. K. Bohme and H. Schwarz, Angew. Chem., Int. Ed., 2005, 44, 2336-2354.

24 H. Schwarz, Isr. J. Chem., 2014, 54, 1413-1431.

25 X. F. Yang, A. Q. Wang, B. T. Qiao, J. Li, J. Y. Liu and T. Zhang, Acc. Chem. Res., 2013, 46, 1740-1748.

26 M. T. Bowers and J. B. Laudenslager, J. Chem. Phys., 1972, 56, 4711-4712.

27 V. Blagojevic, E. Flaim, M. J. Y. Jarvis, G. K. Koyanagi and D. K. Bohme, Int. J. Mass Spectrom., 2006, 249, 385-391.

28 Y.-R. Luo, Comprehensive Handbook of Chemical Bond Energies, CRC Press, Boca Raton, 2007.

29 J. K. Terlouw, W. Heerma, P. C. Frintrop, G. Dijkstra and H. A. Meinema, J. Organomet. Chem., 1974, 64, 205-221.

30 R. J. Ackermann, E. G. Rauh and R. J. Thorn, J. Chem. Phys., 1976, 65, 1027-1031.

31 D. Schroder and H. Schwarz, Angew. Chem., Int. Ed., 1990, 29, 1431-1433.

32 D. Schroder, R. Brown, P. Schwerdtfeger and H. Schwarz, Int. J. Mass Spectrom., 2000, 203, 155-163.

33 J. R. Brown, P. Schwerdtfeger, D. Schroder and H. Schwarz, J. Am. Soc. Mass Spectrom., 2002, 13, 485-492.

34 J. Loos, D. Schroder and H. Schwarz, J. Org. Chem., 2005, 70, 1073-1076.

35 B. Butschke, D. Schroder and H. Schwarz, Organometallics, 2009, 28, 4340-4349.

36 C. Bianchini, K. G. Caulton, C. Chardon, O. Eisenstein, K. Folting, T. J. Johnson, A. Meli, M. Peruzzini, D. J. Rauscher, W. E. Streib and F. Vizza, J. Am. Chem. Soc., 1991, 113, 5127-5129.

37 R. Wesendrup and H. Schwarz, Organometallics, 1997, 16, 461-466.

38 B. Chiavarino, M. E. Crestoni and S. Fornarini, Chem. - Eur. J., 2002, 8, 2740-2746.

39 T. Waters, R. A. J. O'Hair and A. G. Wedd, J. Am. Chem. Soc., 2003, 125, 3384-3396.

40 S. M. Lang, T. M. Bernhardt, R. N. Barnett and U. Landman, Angew. Chem., Int. Ed., 2010, 49, 980-983.

41 A. A. Lysova and I. V. Koptyug, Chem. Soc. Rev., 2010, 39, 4585-4601. 